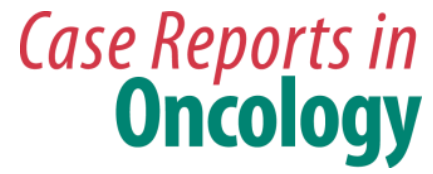

Case Rep Oncol 2019;12:69-75

DOI: 10.1159/000496331

Published online: January 21, 2019

(C) 2019 The Author(s)

Published by S. Karger AG, Basel

www.karger.com/cro

This article is licensed under the Creative Commons Attribution-NonCommercial 4.0 International License (CC BY-NC) (http://www.karger.com/Services/OpenAccessLicense). Usage and distribution for commercial purposes requires written permission.

\title{
Severe Hemorrhagic Cystitis Caused by Cyclophosphamide and Capecitabine Therapy in Breast Cancer Patients: Two Case Reports and Literature Review
}

\author{
Toshihiro Tanaka Yuta Nakashima Hidenori Sasaki Michio Masaki \\ Ai Mogi Kazuo Tamura Yasushi Takamatsu \\ Division of Medical Oncology, Hematology and Infectious Diseases, Department of \\ Medicine, Fukuoka University, Fukuoka, Japan
}

\section{Keywords}

Hemorrhagic cystitis $\cdot$ Cyclophosphamide $\cdot$ Breast cancer $\cdot$ XC $\cdot$ Case report

\begin{abstract}
Combined oral cyclophosphamide and capecitabine (XC) chemotherapy is used for metastatic breast cancer (MBC) patients. We report herein two MBC patients who developed severe hemorrhagic cystitis after XC therapy. Case 1: A 67-year-old woman with MBC had received XC therapy for 2.5 years. After a sudden onset of lower abdominal pain and gross hematuria, cystoscopy revealed a urinary bladder mucosa showing diffuse dilation of the capillaries and a large blood clot. A total dose of $60.8 \mathrm{~g}$ cyclophosphamide had been given and the XC regimen was discontinued immediately. The patient experienced frequent episodes of bladder tamponade over 18 months and underwent continuous bladder irrigation and cystoscopic fulguration. Hyperbaric oxygen therapy (HBOT) provided only temporary relief and the patient subsequently developed hemorrhagic shock. A bilateral ureterostomy was eventually performed.
\end{abstract}




\section{Case Reports in Oncology}

Case Rep Oncol 2019;12:69-75

DOI: $10.1159 / 000496331$

(C) 2019 The Author(s). Published by S. Karger AG, Basel www.karger.com/cro

Tanaka et al: Severe Hemorrhagic Cystitis Caused by Cyclophosphamide and

Capecitabine Therapy in Breast Cancer Patients: Two Case Reports and Literature Review

Case 2: A 65-year-old woman with MBC was given XC for 3 years, but this was discontinued after she developed new lung lesions. The patient was given a total dose of $78.4 \mathrm{~g}$ of cyclophosphamide. A month later, the patient complained of intermittent gross hematuria, which progressed to persistent macroscopic hematuria for 1 week. She underwent continuous bladder irrigation with saline, without an improvement in her bladder tamponade. Subsequently, the bleeding ceased completely after HBOT. Some MBC cases can be controlled for a long time with XC therapy. For those cases, we need to realize that severe hemorrhagic cystitis may occur. Even at a low dose, requires testing periodically for occult blood in the urine to detect the early stages of cystitis.

(c) 2019 The Author(s)

Published by S. Karger AG, Basel

\section{Introduction}

Capecitabine is a prodrug that is metabolized to 5-fluorouracil and is delivered selectively to neoplastic tissue, including breast cancer. Cyclophosphamide, a cytotoxic alkylating agent, is given by intravenous (IV) or oral administration to treat malignancies and autoimmune diseases. Combined, capecitabine and cyclophosphamide (XC) show synergistic antitumor activity [1]. A phase II study of XC in metastatic breast cancer (MBC) patients conducted by the Kyusyu Breast Cancer Study Group revealed a moderate effect on tumors, with manageable side effects [2].

Hemorrhagic cystitis is a complication of high-dose cyclophosphamide therapy by IV, but may also occur with low-dose oral cyclophosphamide. We report herein two MBC patients on long-term XC therapy who developed severe hemorrhagic cystitis resistant to bladder saline irrigations and who required further interventions to control bladder tamponades.

\section{Case Report}

Case 1

A 67-year-old woman had previously undergone a left mastectomy and an axillary lymph node dissection for a left breast cancer at 45. The tumor was positive for estrogen (ER) and progesterone (PR) receptors. Postoperatively, radiotherapy was administered to the residual breast. The cancer recurred as a right lung metastasis 13 years later. The patient underwent an $\mathrm{AC}$ regimen, consisting of adriamycin $\left(60 \mathrm{mg} / \mathrm{m}^{2}\right)$ and cyclophosphamide $\left(600 \mathrm{mg} / \mathrm{m}^{2}\right)$ over six courses, as first-line chemotherapy. With subsequent refractory endocrine therapy, the patient commenced an XC regimen of oral capecitabine (2400 mg/day for 14 days) and cyclophosphamide (100 mg/day for 14 days) every three weeks.

Thirty months later, the patient presented with sudden lower abdominal pain and massive gross hematuria. Urine cultures were negative for bacterial or fungal infections. PCR testing did not detect adenovirus, or BK and herpes simplex viruses in urine. A cystoscopic examination revealed diffuse dilated capillaries in the urinary bladder mucosa (Fig. 1); a bladder wall biopsy ruled out malignancy. Cyclophosphamide-induced hemorrhagic cystitis was diagnosed. The total dose of cyclophosphamide at this point was $60.8 \mathrm{~g}$ during a 912 -day period. $\mathrm{XC}$ therapy was discontinued but the hematuria persisted. Fifteen days later, the patient 


\section{Case Reports in Oncology}

Case Rep Oncol 2019;12:69-75

DOI: $10.1159 / 000496331$

(C) 2019 The Author(s). Published by S. Karger AG, Basel www.karger.com/cro

Tanaka et al: Severe Hemorrhagic Cystitis Caused by Cyclophosphamide and

Capecitabine Therapy in Breast Cancer Patients: Two Case Reports and Literature Review

presented with gross hematuria and signs of a bladder tamponade. The patient's blood hemoglobin level had dropped from 11.0 to $5.1 \mathrm{~g} / \mathrm{dL}$ and she was admitted to hospital. The patient underwent continuous bladder irrigation with saline and drainage of a blood clot. The hematuria resolved but urinary incontinence persisted, with the patient suffering frequent episodes of bladder tamponade. After 18 months, the patient returned to the emergency department complaining of dysuria. Hyperbaric oxygen therapy (HBOT) controlled the hemorrhagic tamponade but the patient subsequently developed hemorrhagic shock. The patient underwent a bilateral ureterostomy after conservative therapies failed to control hemorrhaging. The bladder bleed ceased and the patient was discharged 39 days after surgery. In total, 28 units of packed red blood cells were transfused during the course of treatment. The patient has not experienced a recurrence of gross hematuria in the last 2 years.

Case 2

A 65-year-old woman had been diagnosed with MBC at 57. The tumor was ER+, PR+ and HER2-. Six sequential courses of paclitaxel and docetaxel were administered. After endocrine therapy became refractory, the patient was administered XC consisting of oral capecitabine $(2,400 \mathrm{mg} /$ day for 14 days) and cyclophosphamide (100 $\mathrm{mg} /$ day for 14 days) every three weeks. Thirty-eight months later, new lung lesions developed and XC therapy was discontinued. The cumulative dose of cyclophosphamide at this point reached $78.4 \mathrm{~g}$ for a period of 1,176 days.

One month later, the patient presented with lower abdominal pain and gross hematuria. Cystoscopy was performed due to a blood clot tamponade and the urinary bladder mucosa showed diffuse sloughing with active bleeding. Urine cultures for bacteria or adenovirus were negative. Urine cytology from bladder washings was also negative, and Papanicolaou class II. An abdominal computed tomography scan demonstrated a thickened urinary bladder wall (Fig. 2). Cyclophosphamide-induced hemorrhagic cystitis was diagnosed. Blood hemoglobin levels dropped from 12.9 to $6.4 \mathrm{~g} / \mathrm{dL}$ and a blood transfusion was required. The macroscopic hematuria transiently resolved after transurethral electric coagulation but recurred, and a bladder tamponade developed. The patient underwent continuous bladder irrigation with saline, without improvement in the tamponade. After receiving HBOT daily for 15 days, bleeding ceased completely, with gross hematuria not recurring during the following 6 months.

\section{Discussion}

We describe, for the first time, the development of hemorrhagic cystitis in breast cancer patients after XC therapy. After oral or IV administration, the drug is metabolized by hepatic enzymes to 4-hydroxycyclophosphamide and converted into phosphoramide mustard and acrolein, the latter being the causative agent of cyclophosphamide cystitis.

Hemorrhage usually occurs during or immediately after cyclophosphamide treatment, while delayed hemorrhage may occur in patients on long-term therapy. Stillwell et al. [3] reported on 100 patients with hemorrhagic cystitis induced by cyclophosphamide. Intravenous therapy induced hemorrhagic cystitis at significantly lower doses (average $18 \mathrm{~g}$ ) and after shorter durations (average 12 months) compared to oral therapy (average $90 \mathrm{~g} / 38$ months). Overall, seven Japanese cases of hemorrhagic cystitis caused by oral cyclophosphamide have 


\section{Case Reports in Oncology}

Case Rep Oncol 2019;12:69-75

DOI: $10.1159 / 000496331$

(C) 2019 The Author(s). Published by S. Karger AG, Base www.karger.com/cro

Tanaka et al.: Severe Hemorrhagic Cystitis Caused by Cyclophosphamide and

Capecitabine Therapy in Breast Cancer Patients: Two Case Reports and Literature Review

been reported in the English medical literature [4-9] (Table 1). In Japanese patients, the average total dose was $157 \mathrm{~g}$ and the average duration of cyclophosphamide therapy was 108 months before the development of hemorrhagic cystitis. On the other hand, Kimura et al. [10] investigated mucosal changes in patients subjected to cyclophosphamide therapy in relation to its duration and accumulating. Cyclophosphamide-induced cystitis with no hematuria insidiously progressed in patients who received cyclophosphamide orally at a total dose of more than $40 \mathrm{~g}$ and/or for longer than 36 months. The present two cases received oral $100 \mathrm{mg}$ daily cyclophosphamide for 2 weeks, followed by 1 week rest, for 30 or 38 months, equal to $60.8 \mathrm{~g}$ or $78.4 \mathrm{~g}$ cumulative doses, respectively. This is equivalent to the average total dose of cyclophosphamide reported by Kimura et al. to cause hemorrhagic cystitis. Moreover, in case 1, the patient had received six courses of AC therapy 8 years prior to this present episode, which may have contributed to cyclophosphamide-induced cystitis.

Interindividual variation in the development of hemorrhagic cystitis presently remains unknown. Ekhart et al. [11] assessed 16 selected polymorphisms in nine genes of putative relevance to the activities of antineoplastic agents, including cyclophosphamide metabolism, in 113 patients who were treated with cyclophosphamide-based chemotherapy. The $A L D H 3 A 1 * 2$ allele (allelic frequency $21.2 \%$ ) was associated with an increased risk of hemorrhagic cystitis when compared to patients with wild-type alleles (odds ratio: 11.95).

In contrast to acute changes in the urinary bladder, long-term exposure to acrolein causes a diffuse inflammation of the bladder mucosa leading to severe hemorrhagic cystitis that often persists despite the discontinuation of cyclophosphamide therapy. Several therapeutic options exist for the treatment of cyclophosphamide-induced severe hemorrhagic cystitis. Regarding local therapy other than electrocauterization of bleeding points by fulguration, intravesical instillation with alum, silver nitrate, phenol, prednisolone, prostaglandins and formalin have been used to control severe hemorrhage; however, hemorrhagic cystitis often failed to respond [12]. Conversely, systemic treatment with HBOT of cyclophosphamide-induced hemorrhagic cystitis and has yielded good results [13, 14, 15].

Severe hemorrhagic cystitis as an iatrogenic complication should be avoided. We examined the relationship between bladder wall thickness and urinary occult blood in case 2 (Fig. 3). When microscopic hematuria persisted, the degree of thickening of the bladder wall tended to progress. Stillwell et al. recommended cystoscopy be done in all patients with cyclophosphamide exposure showing microscopic hematuria. Cystoscopy would allow observation of the degree of bladder inflammation and be useful to a physician deciding whether cyclophosphamide treatment should be continued when such therapy is critical.

In summary, high-dose cyclophosphamide can induce hemorrhagic cystitis; however, this can also occur with low-dose cyclophosphamide therapy such as XC for breast cancer patients. Severe hemorrhagic cystitis is a challenging condition to treat and may give rise to serious complications such as bladder tamponade and significant contraction of the bladder associated with urinary frequency, leading to prolonged hospitalization and the occasional lethal event. Because XC therapy is used to control disease progression in the long term in some MBC patients, we need to be mindful of the severe hemorrhagic cystitis that may occur in such cases. It is of the utmost importance to periodically test urine for occult blood to detect cystitis in MBC patients since the early cessation of cyclophosphamide therapy may prevent the development of severe mucosal damage. 


\section{Acknowledgement}

None.

\section{Statement of Ethics}

The authors have no ethical conflicts to disclose.

\section{Disclosure Statement}

The authors have no conflicts of interest to declare.

\section{References}

1 Endo M, Shinbori N, Fukase Y, Sawada N, Ishikawa T, Ishitsuka H, et al. Induction of thymidine phosphorylase expression and enhancement of efficacy of capecitabine or 5'-deoxy-5-fluorouridine by cyclophosphamide in mammary tumor models. Int J Cancer. 1999 Sep;83(1):127-34.

2 Tanaka M, Takamatsu Y, Anan K, Ohno S, Nishimura R, Yamamoto Y, et al.; Kyushu Breast Cancer Study Group. Oral combination chemotherapy with capecitabine and cyclophosphamide in patients with metastatic breast cancer: a phase II study. Anticancer Drugs. 2010 Apr;21(4):453-8.

3 Stillwell TJ, Benson RC Jr. Cyclophosphamide-induced hemorrhagic cystitis. A review of 100 patients. Cancer. 1988 Feb;61(3):451-7.

4 Kimura M, Morishita H, Kurokawa I, Fujioka H, Takahashi K. Hyperbaric oxygen therapy in the successful treatment of cyclophosphamide-induced hemorrhagic cystitis: report of two cases (in Japanese with English abstract). Rinsyo Hinyokika. 1997;51:959-61.

5 Kuroda I, Kuwata Y, Kakehi Y. Hyperbaric oxygen therapy for Wegener's granulomatosis with cyclophosphamide-induced hemorrhagic cystitis. Int J Urol. 2002 Aug;9(8):470-2.

6 Matsushita J, Ochi T, Tanji N, Nishio S, Tachou T, Yokoyama M. Hyperbaric oxygen therapy for cyclophosphamide-induced hemorrhagic cystitis: A case report (in Japanese with English abstract). Rinsho Hinyokika. 2004;58:155-7.

7 Takasugi S, Kunishima Y, Shimizu T, Takahashi A, Ito N, Tsukamoto T. Hyperbaric oxygen therapy succesful in the treatment of two cases of hemorragic cystitis (in Japanese with English abstract). Rinsho Hinyokika. 2005;59:143-5.

8 Kitsukawa S, Samejima T, Ito T, Aoyagi T. Hyperbaric oxygen therapy for cyclophosphamide-induced hemorrhagic cystitis: A case report (in Japanese with English abstract). Rinsho Hinyokika. 2007;61:449-51.

9 Takagi K, Kojima K, Yuhara K, Shibata Y. [Long-term oral low-dose cyclophosphamide-induced hemorragic cystitis which was successfully treated by ureterostomy: a case report]. Hinyokika Kiyo. 2012 Dec;58(12):687-90.

10 Kimura M, Tomita Y, Morishita H, Takahashi K. Presence of mucosal change in the urinary bladder in nonhematuric patients with long-term exposure and/or accumulating high-dose cyclophosphamide. Possible significance of follow-up cystoscopy on preventing development of cyclophosphamide-induced hemorrhagic cystitis. Urol Int. 1998 Oct;61(1):8-11.

11 Ekhart C, Rodenhuis S, Smits PH, Beijnen JH, Huitema AD. Relations between polymorphisms in drugmetabolising enzymes and toxicity of chemotherapy with cyclophosphamide, thiotepa and carboplatin. Pharmacogenet Genomics. 2008 Nov;18(11):1009-15.

12 Yazawa H, Nakada T, Sasagawa I, Miura M, Kubota Y. Hyperbaric oxygenation therapy for cyclophosphamide-induced haemorrhagic cystitis. Int Urol Nephrol. 1995;27(4):381-5.

13 Davis M, MacDonald H, Sames C, Nand K. Severe cyclophosphamide-induced haemorrhagic cystitis treated with hyperbaric oxygen. N Z Med J. 2011 Aug;124(1340):48-54. 


\section{Case Reports in Oncology}

Case Rep Oncol 2019;12:69-75

DOI: $10.1159 / 000496331$

(c) 2019 The Author(s). Published by S. Karger AG, Basel www.karger.com/cro

Tanaka et al: Severe Hemorrhagic Cystitis Caused by Cyclophosphamide and

Capecitabine Therapy in Breast Cancer Patients: Two Case Reports and Literature Review

14 Ajith Kumar S, Prasanth P, Tripathi K, Ghosh P. Hyperbaric oxygen-A new horizon in treating cyclophosphamide-induced hemorrhagic cystitis. Indian J Urol. 2011 Apr;27 (2):272-3.

15 Kalayoğlu-Beşişik S, Abdul-Rahman IS, Erer B, Yenerel MN, Oğuz FS, Tunç M, et al. Outcome after hyperbaric oxygen treatment for cyclophosphamide-induced refractory hemorrhagic cystitis. J Urol. 2003 Sep;170(3):922.

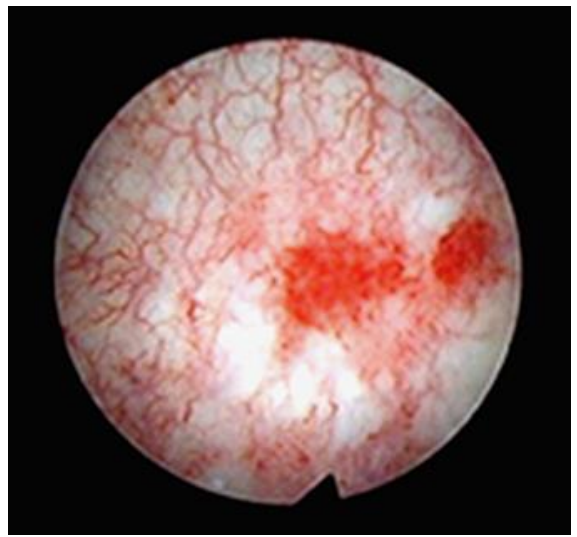

Fig. 1. Cystoscopic examination in case 1 showed erythematous and diffuse dilation of capillaries in the urinary bladder mucosa.

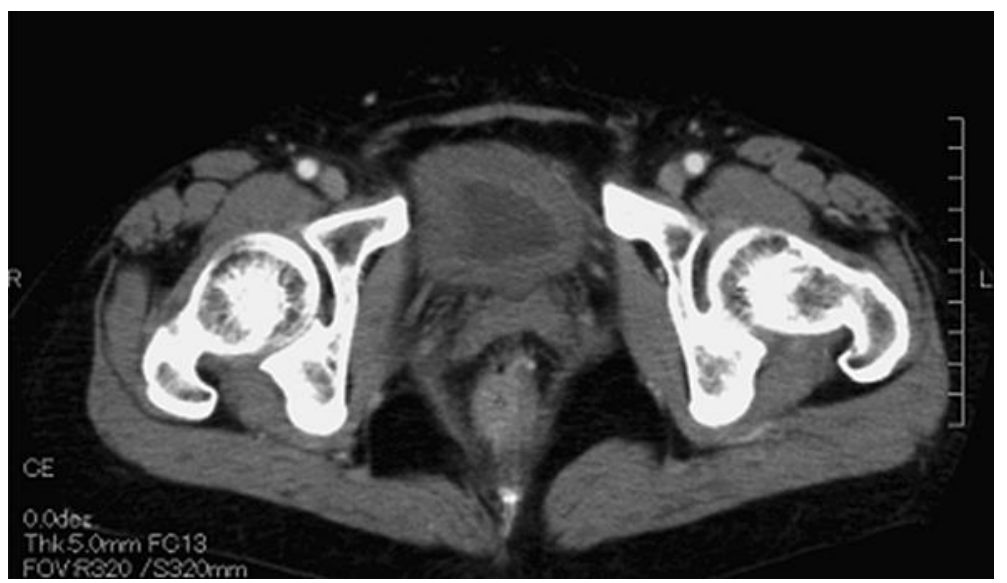

Fig. 2. A computed tomography (CT) scan in case 2 demonstrating marked bladder wall thickening. 


\section{Case Reports in Oncology}

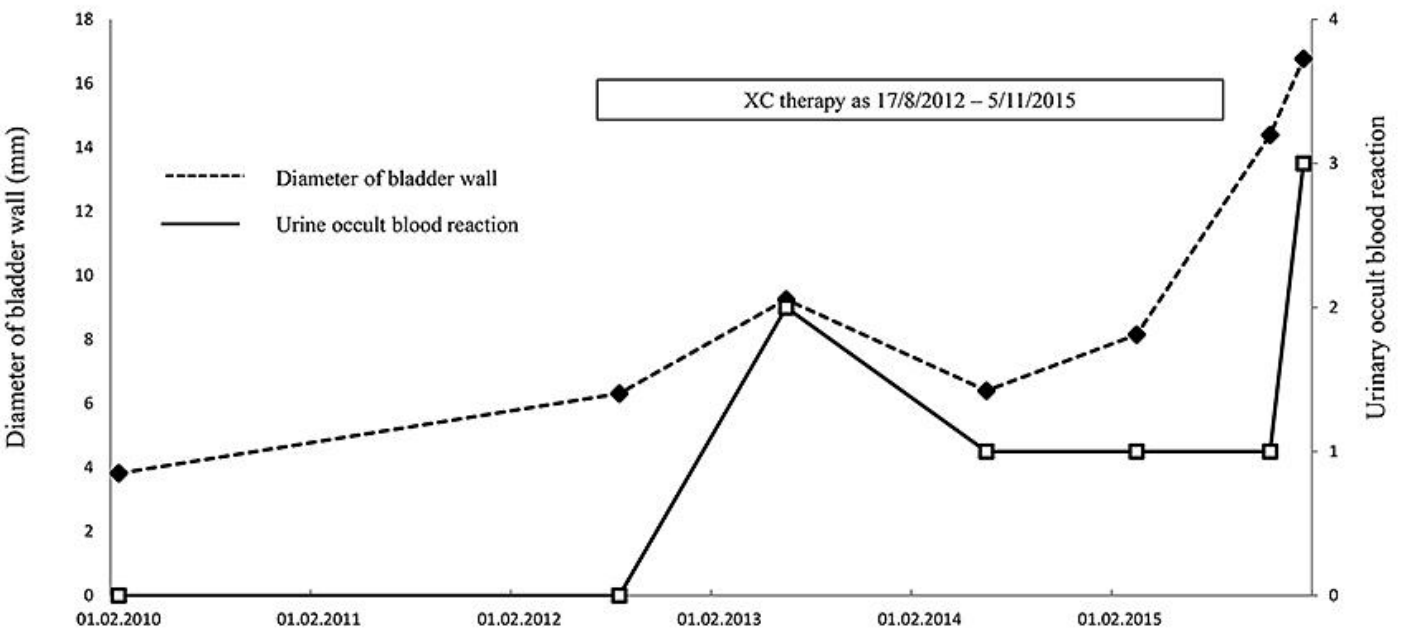

Fig. 3. Relationship between the thickness of the bladder wall and microscopic hematuria in case 2.

Table 1. Reports of hemorrhagic cystitis caused by oral cyclophosphamide in Japanese patients

\begin{tabular}{lllllcrl}
\hline $\begin{array}{l}\text { Publication } \\
\text { year }\end{array}$ & Author & $\begin{array}{l}\text { Age, } \\
\text { years }\end{array}$ & Sex & Disease & $\begin{array}{l}\text { Total } \\
\text { dose, g }\end{array}$ & $\begin{array}{l}\text { Duration, } \\
\text { months }\end{array}$ & Treatment \\
\hline 1997 & Kimura [4] & 71 & F & Multiple myeloma & 44.6 & 154 & TUC, PGF2 $\alpha$, HBOT \\
1997 & Kimura [4] & 42 & F & AIHA & 237 & 111 & HBOT \\
2002 & Kuroda [5] & 49 & M & Wegener's granulomatosis & 360 & 216 & Alum, HBOT \\
2004 & Matsushita [6] & 65 & F & Rheumatoid arthritis & 73 & 48 & TUC, HBOT \\
2005 & Takasugi [7] & 49 & F & Wegener's granulomatosis & 197 & 106 & Alum, HBOT \\
2007 & Kitsukawa [8] & 58 & F & SLE & 125 & 84 & HBOT \\
2012 & Takagi [9] & 80 & M & Multiple myeloma & 65 & 43 & Alum, TUC, Ureterostomy \\
\hline & & Average & & & Average & Average & 108 \\
& 59 & & & 157 & 108 &
\end{tabular}

AIHA, Autoimmune hemolytic anemia; SLE, Systemic lupus erythematosus; TUC, Transurethral coagulation; PGF2 $\alpha$, Prostaglandin F2 $\alpha$; HBOT, Hyperbaric oxygen therapy; Alum, Aluminum hydroxide. 